\title{
German Proposal for a Standard Approach for Solvency II
}

\author{
Thomas Schubert and Gundula Grießmann \\ Business Administration Institute, German Insurance Association (GDV), Friedrichstrasse 191, 10117 \\ Berlin, Germany. \\ E-mail: t.schubert@gdv.org
}

The German insurance industry has dealt intensely with the creation of a new supervisory model for European insurance companies since 1997 and released the so-called GDVmodel in 2002. At the end of 2005, a completely redesigned proposal for a Solvency II compatible standard approach was published. For this new release, the GDV worked together with the German supervisory authority (BaFin) and the Association of the German actuaries (DAV). The objective of this paper is to show the progress of the work aimed at developing this standard model. Market risk, credit risk, underwriting risk life and non-life and operational risk are included in the approach as CEIOPS proposed. The main focus is on modelling the market risk, especially the interest-rate risk. The paper wants to show how the ALM risk, which is quite important for the insurance industry, could be modulated in a simple but meaningful way with the help of a duration approach.

The Geneva Papers (2007) 32, 133-150. doi:10.1057/palgrave.gpp.2510116

Keywords: German standard approach Solvency II

\section{Introduction}

Within the scope of "Solvency II", it has been provided for that insurers calculate the risk-based own funds needed using a standard model or their own internal risk model.

The working groups of insurance supervisors (CEIOPS - Committee of European Insurance and Occupational Pension Supervisors) have been discussing the actual design of this new system since the summer of 2004 and published a first interim report on their discussion - inter alia on the standard model and on requirements for internal models - in November 2005. ${ }^{1}$ This report mentions the risk categories to be quantified and points out several possibilities of how these might be reflected.

GDV started its first reflections on a risk-based standard approach as early as 1997 , setting itself the goal to initiate a redesign of insurance supervision by suggesting an approach, which is, to a greater extent, based on risk management models. With this in mind, a risk-oriented standard model for life and casualty/property/accident insurers has been developed allowing for the particularities of specific classes. Since its publication in August 2002, the so-called "GDV model", has been applied by numerous insurance companies in their risk management practice. The approach has

\footnotetext{
${ }^{1}$ Cf. CEIOPS (2005a).

${ }^{2}$ Cf. GDV Model (2002).
} 
met with a positive response at both national and international levels. Moreover, GDV has brought the model into the national and European debates on a new system of insurance supervision for Europe within the scope of the Solvency II project.

Against this background, the model was revised in the spring of 2004 . The objective was to check the model, which is now a few years old, to find out what adjustments should be made to allow for practical experience, the ongoing discussion and the changed economic environment. The new approach is to be understood as a proposal for a standard model compatible with "Solvency II" and was published on the website of the GDV at the end of 2005. ${ }^{3}$ Also, the concept presented is compatible with the preparatory work done by the International Actuarial Association (IAA). ${ }^{4}$

The objective of this article is to show the main characteristics of the standard approach. The focus is on modelling the market risk, especially the interest-rate risk. The article wants to show how the ALM risk, which is important for the insurance industry, could be modulated in a simple but meaningful way with the help of a duration approach.

The approach has the following general characteristics that plead for implementing the approach at European and national levels as a result of "Solvency II":

- The approach, which has been developed as a probability-and coefficient-based model, includes - unlike a scenario-based approach - all relevant risks and is at the same time sufficiently simple.

- The approach has a modular structure, so that it is possible to incorporate national particularities of other European countries.

- The approach adopts - as required due to risk-based considerations - a marketvalue point of view, but derives such market values - in simplified fashion - from Commercial Code figures. Thus, companies which do not already prepare their balance sheets according to IAS/IFRS and do not have to move to international accounting rules in the foreseeable future either are not urged to switch to IAS/ IFRS.

- As required by the EU Commission, aspects related to Asset Liability Management (ALM) are reflected. This is effected as part of the modelling of change-in-interestrates risks for fixed interest-bearing investments.

- The model allows for correlation effects in a conservative way, thus reflecting risk balancing processes in the insurance company.

- Incentives for the company to develop an internal model are provided by simplifying modelling and conservative parametrization.

- The parameters of the model have been - as far as this is necessary for their easy handling - predetermined in the model. In addition - where this seems necessary due to risk-based considerations - data of the individual company are used to avoid any simplifying averaging in determining risk factors (personalized factor-based model). The input data of the individual company have been chosen in such a way as to ensure that they may be easily established by the insurance company and easily verified by the supervisory authority. For instance, in the life model, internal data

\footnotetext{
${ }^{3}$ Cf. Standard Approach (2005).

${ }^{4}$ Cf. IAA (2004).
} 
are used to determine the risk factors included in the calculation risk. In the non-life model the technical risk is determined on the basis of the fluctuations of the combined ratio in the individual company.

- The computational formula will be made available to the companies in Excel, so that the burden put on insurance companies will be reduced.

\section{Fundamental characteristics of the model}

The draft standard model compatible with "Solvency II" to calculate the required risk capital (solvency capital requirements - SCR) has the following characteristics, in addition to those already mentioned:

- As risk measure the value at risk is chosen, in line with the approach pursued at European level. ${ }^{5}$

- The risk capital needed to cover the individual risks is aggregated on the assumption of correlations to an aggregate capital requirement using the covariance formula.

- The supervisory model takes - as required at European level - a one year point of view.

- In both the life and the casualty/property/accident models, investment risks and operational risks are reflected according to the same approach (G1 and G2 risks) (see Chart 1). In modelling technical risks, the particularities of specific classes are allowed for in each case (life: L and non-life: NL risks).

\section{Modelling of the investment risk}

The G1 risk includes all individual risks, which may arise for insurance companies due to developments on the capital markets. It includes both pure investment risks, which

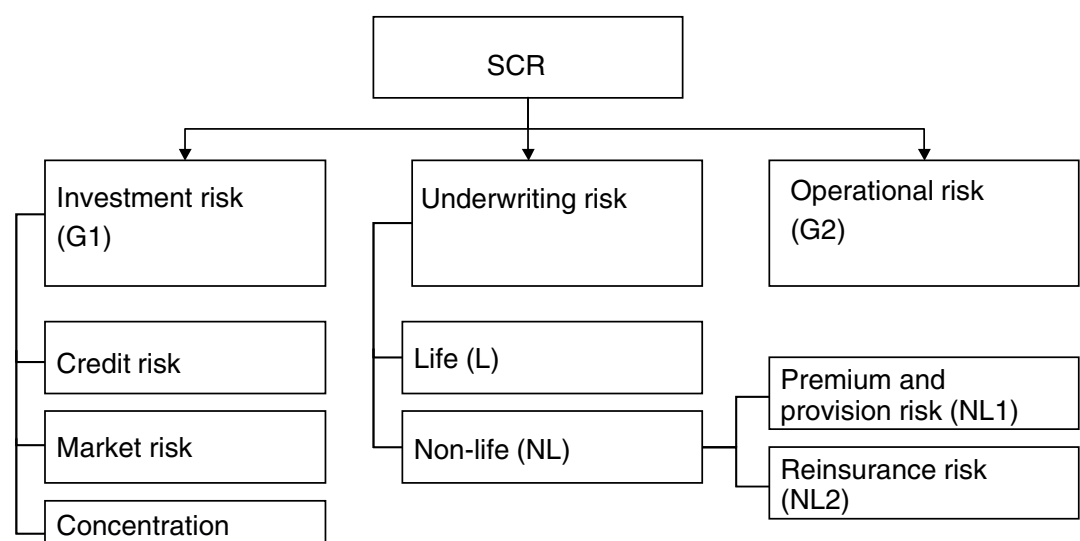

Chart 1. Structure of the standard model.

\footnotetext{
${ }^{5}$ Cf. CEIOPS (2005b).
} 
affect only the company's assets, and other risks, which also have an impact on the company's liabilities, and must therefore be seen in the context of asset-liability management. The latter category within the standard model comprises the interest-rate risk. All other G1 risk types fall under the former category, the pure investment risk.

Capital market-related risks can be classified as follows:

- the credit risk, caused by changes in the debtor's credit rating, up to the complete failure of borrowers;

- the market risk, caused by volatility in the capital markets, which is divided into:

- the risk of price changes of fixed-interest investments: the risk of changes in the interest rate (increase or decrease in interest rates) in the light of ALM considerations;

- the risk of value changes of real estate;

- the foreign currency risk, caused by fluctuations in exchange rates, which are not entirely hedged;

- concentration risk, due to very high individual exposures.

The input data for investments are to be based on an economic approach. The investment classes considered are real estate, equities and fixed-income titles, divided into rating classes and mortgages. "Fixed-income titles" are understood to mean all fixed-interest titles (bonds issued, e.g., by government issuers, banks and other companies, mortgage loans, other receivables, e.g., notes payable and registered securities, policy loans and cash positions), with no distinction made between investments that are held directly and indirectly. The available amounts (=market values) are to be assigned to the individual investment categories.

For example:

- Mixed funds are to be divided into equities, bond and real estate shares.

- Property management companies are assigned to the "real estate" category.

- Derivatives are considered with delta weights (exception: equities portfolios hedged with a put option).

- Cash positions in funds and short-term investments are classified as "fixed-income titles." The modified duration of those investments is defined as " 0 ".

- Policy loans are also classified as "fixed-income titles". The duration of the PEXP' is used for the modified duration of those loans (conservative method).

- Affiliated companies and holdings are generally treated as "equities".

"Alternative investments" and other investments not yet listed are special cases. They are assigned to the aforementioned investment classes according to their risk.

\section{Credit risk}

The credit risk is calculated for fixed-income titles. This category includes the risk that the debtor will not be able to meet its interest and principal payments, for example, in

\footnotetext{
${ }^{6}$ PEXP is the performance index of German covered bonds.
} 
the event of bankruptcy (the "default risk"), as well as the risk of an increase in credit spread, which may be caused by a simple market change or by a reduction in the rating of the issue (migration risk).

The essential indicator of the issuer's credit risk is the issuer's credit rating. In addition, issue ratings are assigned for nearly all new issues on the bond market. Due to their widespread use on the capital market, ratings are a good tool for assessing credit risk.

The starting point for determination of the credit risk in the SCR model is the rating of an issue. If no such rating is defined, an external issuer rating can be used as an alternative. If no external ratings exist for either the issue or the issuer, the title should initially be classified as "non-rated". However, subject to requirements with respect to reviewability and transparency, the company may also issue internal ratings. For example, unrated titles with particular features or a specific cover pool may be assigned to the Investment Grade category (e.g., assignment of fixed-income securities with maintenance obligation of public institutions or guarantor liability to the rating class AAA or comparable ratings). In the case of profit participation certificates and subordinated loans as well, consideration must be given to the specific terms and conditions of issue, while, in accordance with the procedure of rating agencies, a reduction by two "notches" has to be made from the rating of issuers.

Credit risks are modelled in the SCR method using a beta distribution. They are calculated separately and then added together to arrive at the overall risk. The input data for the model are the recovery rates, historical default rates and the minimum number of issuers per rating classes, data that may have to be updated every year (Table 1).

Mortgages are divided into "1a mortgages" and other mortgages. 1a mortgages are loans for which the insurance company's claim is entered in the Land Register with top priority and the amount of the loan does not exceed 60 per cent of the collateral value of the property. "Other mortgages" are, in turn, divided into "non-1a mortgages," that is, mortgages whose loan value ratios are between 60 and 80 per cent, and mortgages with loan value ratios above 80 per cent of the market value. Mortgages not admitted for the guarantee funds are assigned to the loan value $\geqslant 80$ per cent category. The latter group is divided into mortgages in default for over 90 days and other mortgages. The SCR factors used in this model take into account the improved realization possibilities and the collateralization of the loans through mortgages (see Table 2).

Table 1 Current risk factors

\begin{tabular}{lcc}
\hline Fixed income rating classes & Risk factor $(R F)(\%)$ & Risk bearer $(R B)$ \\
\hline (not including mortgages and policy loans) & & Market value \\
AAA & 0.00 & Market value \\
AA & 0.28 & Market value \\
A & 3.30 & Market value \\
BBB & 6.56 & Market value \\
BB & 10.16 & Market value \\
B & 22.23 & Market value \\
CCC and lower (including issuers in/near bankruptcy) & 34.75 & Market value \\
Unrated & 10.56 & . \\
\hline
\end{tabular}


Table 2

\begin{tabular}{lcc}
\hline Mortgage rating classes & Risk factor $(R F)(\%)$ & Risk bearer (RB) \\
\hline $\begin{array}{l}\text { la mortgages, that is top-priority and loan value } \\
\text { ratio } \leqslant 60 \%\end{array}$ & 0.50 & Market value \\
Mortgages with loan value ratio between 60 and $80 \%$ or & & Market value \\
secondary priority with loan value ratio $\leqslant 60 \%$ & & Market value \\
Thereof in default ( $>90$ days) & 7.0 & Market value \\
Other & 1.0 & Market value \\
Mortgages with loan value ratios above $80 \%$ & & Market value \\
Thereof in default $(>90$ days) & 14.0 & Market value \\
Other & 2.0 & \\
\hline
\end{tabular}

The total SCR needed for the default risk is comprised of the total of the individual SCRs (=the production of the risk factor and risk bearer). Use of that total is based on the assumption that the individual SCRs are fully correlated (or nearly so).

\section{Market risk}

The market risk means the risk to which an insurance company is exposed due to fluctuations in the stock, fixed-interest-bearing investments and real estate markets.

\section{Shares}

To reflect the market change risk the volatilities (17 per cent) and expected earnings (7.3 per cent) in the stock market - depending on the respective yield in the bond market - have been estimated on the basis of historical data. In calculating the earning-capacity value, the risk premium as compared with the yield of 10 years' fixedinterest-bearing investments has been taken as a basis. The risk factor (31.8 per cent) determined on this basis is then multiplied by the market value of the shares.

\section{Real estate/property}

In determining the risk arising from real estate and property, a similar approach is applied as for the share risk. Here too, the volatilities ( 7.4 per cent) and expected earnings (5.5 per cent) are estimated by means of experience gathered in the past. Again, the market values of the real estate are weighted by the risk factor (13 per cent) thus calculated.

\section{Fixed-interest-bearing investments}

An isolated analysis of the impact of changes in market interest rates on assets is not sufficient. Instead, the impact on assets and liabilities must be examined simultaneously. An increase or decrease in the capital market interest rate means that the market value of both fixed-interest securities in the company's investment portfolio 
and that of the company's liabilities will change. According to the model's conception, the company has an interest change risk if the modified durations or market values of assets and liabilities are different ("not hedged"). ${ }^{7}$

If the duration on the asset side is longer than that for liabilities, the company suffers a net loss in market value in the event of a rise in interest rates; this risk must be measured accordingly. For non-life insurers, this generally concerns all lines except for liability insurance (including motor liability insurance) and accident insurance with premium refunds (APR). For life insurers, asset duration is generally shorter than liability duration (in terms of guaranteed benefits). Nevertheless, a rise in market interest rates may pose a risk in the event of cancellations and guaranteed surrender values. ${ }^{8}$ Therefore, the risk of interest-rate changes for life insurers is also known as the "ALM risk due to cancellation".

By the same token, a decline in capital market interest rates represents a risk if asset duration is shorter than the duration on the liability side. This is generally the case for life insurers and, in the case of non-life insurers, for liability insurance and accident insurance with premium refunds.

Additional security measures such as swaptions are not sufficiently captured by the duration-based method and consequently by the standard method. These should be taken into account within the supervisory ladder or through internal models. ${ }^{9}$

Therefore, the following procedure is used:

- The various lines are combined into two categories: non-life insurers (not including accident insurance with premium refunds) and life insurers, as well as accident insurance with premium refunds. Accident insurance with premium refunds is to be calculated in a manner identical to the life model below.

- For each category, a distinction is made between a rise and decline in interest rates. - Since the risks are entirely opposite, the higher of the two net risks is taken.

The change in market values as a result of a change in interest rates $\Delta$ - that is, negative $\Delta$ in the event of a decrease, positive $\Delta$ in the event of an increase in interest rates - can generally be quantified in the following way:

- market value change for fixed-income titles on the asset side

$$
\delta M V_{F I}=-M V_{F I} \cdot D_{F I}^{\bmod } \cdot \Delta
$$

\footnotetext{
${ }^{7}$ This simple duration method only describes the risk as a first approximation (no convexity, no separate types of terms). However, a more detailed method should not be chosen for the standard model, since most companies cannot provide the other information that would be necessary for such a detailed method, for example actuarial cash flow for the various types of terms.

${ }^{8}$ It should be kept in mind in this regard that the probability of cancellation may increase sharply relative to historical values in the event of an interest shock. Due to the increase in information available to customers (e.g., recommendations from consumer advocacy groups) and a net interest rate that is clearly lower than in recent decades, it is assumed that an increasing number of life insurance customers will terminate their contracts in the event of an upwards interest shock, despite losing their tax advantage, in order to themselves invest in fixed-interest titles at higher returns.

${ }^{9}$ As already stated, options are generally assessed at delta level.
} 
- market value change for insurance commitments

$$
\delta M V_{L I}=-M V_{L I} \cdot D_{L I}^{\bmod } \cdot \Delta^{\prime}
$$

where $D_{F I}^{\text {mod }}$ is the modified duration of the fixed-income portfolio, ${ }^{10} D_{L I}^{\text {mod }}$ the modified duration of the insurance commitments portfolio $(L I),{ }^{11} M V_{F I}$ the market value of fixed-income securities prior to interest shock, $M V_{L I}$ the market value of insurance commitments $(L I)$ prior to shock, and $\Delta, \Delta^{\prime}$ the market interest-rate change on the assets or liabilities side.

\section{Remarks:}

- It has to be kept in mind that a negative modification of the market value (i.e., an interest-rate increase) is a loss on the assets side and a profit on the liabilities side (decrease in creditors). On the other hand, a positive modification of the market value (caused by a decline in interest-rates) is a profit on the assets side and a loss on the liabilities side.

- Both formulas for market value changes can be considered as a product from risk factor (i.e., market interest-rate changes $\Delta, \Delta^{\prime}$ on the assets or liabilities side) and risk bearer (negative product from market values and modified durations).

- From these two formulas, it is derived that the modified durations are the measure for the changes of market values in the event of an interest shock. If, for example, for an unhedged portfolio the modified duration of the liabilities side is significantly higher than that of the assets side, as is the case for life insurers, the variation on the liabilities side is larger than on the assets side by this measure. Therefore, the generally high figures for market values result in significant ALM risks.

If the decrease in market interest rates is determined based on a significance level of 0.5 per cent ("interest shock"), the risk of a decline in interest rates can be quantified using the above method. In the present model, the development of interest rates for 10year titles is represented using a Black-Karasinski distribution. The assumed change in interest rates equals the difference between the market interest rates at the time of assessment and the interest rate calculated using the Black-Karasinski method. The question of the spread change $\Delta-\Delta^{\prime}$ is examined separately.

Reduction-of-interest-rates/risk The reduction-of-interest-rates risk is reflected as follows (Chart 2):

The SCR for the risk of a decrease in interest rates is calculated as the difference between the increase in market values on the liabilities side (=loss) and the increase in market values of assets (=profit). In the model, only fixed-income securities on the

${ }^{10}$ With special consideration for the duration of cash positions $(D=0)$, forward deposits $(D=0)$ and policy loans ( $D=$ mod. duration of PEXP). With respect to mortgage loans the cancellation option after 10 years must be explicitly taken into account. This has a direct impact on the modified duration of fixed-income securities.

11 The non-life insurance lines have been divided into three groups in accordance with the duration of their provisions: short-tail, medium-tail and long-tail lines. 


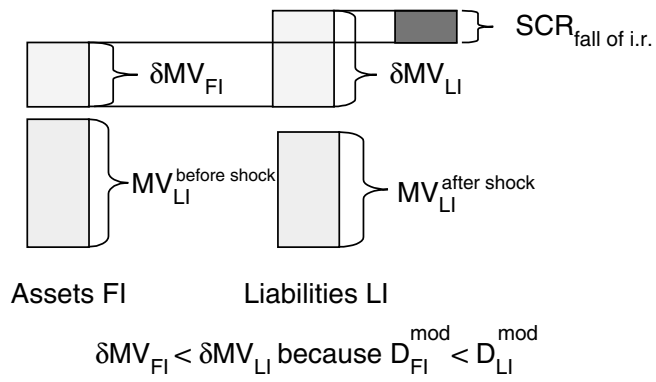

Chart 2. Calculation of the risk capital in the case of a reduction of interest rates.

assets side are considered as being interest sensitive. Therefore, equities and real estate have a modified duration of zero in the standard model.

The SCR in the event of a decrease in interest rates is calculated according to the method of modified duration by the following formula:

$$
\begin{aligned}
S C R_{\text {Interest-rate decline }}= & \max \left(\Delta M V_{L I}-\Delta M V_{F I} ; 0\right) \\
& -E_{\text {interest requirement }} \\
= & \max \left(M V_{F I} \cdot D_{F I}^{\text {mod }} \cdot \Delta\right. \\
& \left.-M V_{L I} \cdot D_{L I}^{\text {mod }} \cdot \Delta^{\prime} ; 0\right) \\
& -E_{\text {interest requirement }}
\end{aligned}
$$

where $\Delta$ is the change in interest rates on the assets side, calculated on the basis of the 0.5 per cent significance level of the 10-years Euro swap rate (in this case negative), $\Delta^{\prime}$ the change in interest rates on the liabilities side (for non-life insurers $\Delta=\Delta^{\prime}$ is assumed), $\delta \Delta$ the spread reduction in the event of declining interest rates and $\mathrm{E}_{\text {interest }}$ req. the income from basic requirement.

The maximum value is set at zero with a view, in the case of $D_{F I}^{m o d}>D_{L I}^{m o d}$, to limiting the resulting reduction of requirements to zero in accordance with a conservative approach.

As the average residual term of insurance commitments is definitely above 10 years, the assumption $\Delta=\Delta^{\prime}$ is no longer sufficiently conservative for life insurers. Observations made in Denmark and the United Kingdom suggest that a decline in interest rates may also result in a spread reduction between terms of 10 years and longer, even though it has not been possible yet to make these observations in marked declining interests scenarios in the Euro area. For this reason, the model assumes the halving of the spread between the interest rate used for the valuation of liabilities $\left(r_{\text {liabilities }}\right)$ and the 10-years Euro swap rate. ${ }^{12}$

\footnotetext{
12 Since formula (5.3) relates to the case of a decrease in interest rates, it would only generate an additional value in the case of a spread change if the interest-rate decrease were smaller at the shorter end of the curve than at the longer end. This cannot be observed empirically for terms under 10 years. Therefore, it is sufficiently conservative to assume equal absolute interest-rate changes on the asset and liability sides for non-life insurers.
} 


$$
\begin{aligned}
\Delta^{\prime}= & \Delta-1 / 2 \cdot S P_{\text {interest-rate decline }} \cdot \max \\
& \times\left(r_{\text {liabilities }}-10-\text { years Euro swap }- \text { Rate } ; 0\right)
\end{aligned}
$$

where $r_{\text {liabilities }}$ is the market interest rate according to the residual terms of liabilities, ${ }^{13}$ $S P_{i . r .}$ decrease the class factor $(S P=0$ for non-life insurers and $S P=1$ for life and accident insurers with premium return) and $\Delta$ the change of interest rates based on the 0.5 per cent significance level - in the event of declining interests a negative value.

If for the life insurer the insurance commitments are only shown at book values, the reserves comprised in the insurance commitments can be approximated by

$$
\begin{gathered}
B V_{L I}=\left(1+\left(r_{\text {liabilities }}-M R Z\right) D_{L I}^{\text {mod }}\right) M V_{L I} \\
\text { Reserves }_{L I}=B V_{L I}-M V_{L I} \\
\text { Reserves }_{L I}=B V_{L I}\left(1-\frac{1}{1+\left(r_{\text {liabilities }}-M R Z\right) \cdot D_{L I}^{\text {mod }}}\right)
\end{gathered}
$$

where $M R Z$ is the average technical interest rate of the insurance portfolio and $B V_{L I}$ the (interest-bearing) liabilities at book values.

Increase-in-interest-rates risk The SCR for the interest-rate increase risk is calculated as the difference between the decline in the market values of assets (=loss) and the decline in market values of liabilities (=profit) plus the $S C R$ for lapses (applies only to life and accident insurance with premium return). ${ }^{14}$ The first term is calculated as follows:

$$
\begin{aligned}
S C R_{\Delta M V, \text { interest-rate increase }} & =-\Delta M V_{F I}+\Delta M V_{L I} \\
& =M V_{F I} \cdot D_{F I}^{\text {mod }} \cdot \Delta-M V_{L I} \cdot D_{L I}^{\text {mod }} \cdot \Delta
\end{aligned}
$$

where $\Delta$ is the interest change based on a significance level of 0.5 per cent, in this case positive. ${ }^{15}$

In this case as well, the potential interest shock (in this case upward) is defined using a Black-Karasinski model.

Since the modified duration of interest-bearing liabilities is generally higher than that of the fixed-income portfolio for life insurers, the formula (5.8) yields a negative value, that is, an income. In addition, an interest-based cancellation risk must be taken into account.

${ }^{13}$ The Euro swap rate as of 31 December of the relevant financial year, in accordance with the residual term of the liabilities; the residual term of liabilities is calculated as a weighted mean. For life insurers a residual term of 10 years is assumed for term insurance and a residual term of 15 years for other types of insurance.

${ }^{14}$ For the interest-rate increase risk, too, only fixed-interest titles are considered interest-sensitive.

${ }^{15}$ Since formula (5.5) relates to the case of a rise in interest rates, it would only generate an additional value in the case of a spread change if the interest-rate increase were smaller at the shorter end of the curve than at the longer end. This cannot be observed empirically for any type of term. Therefore, it is sufficiently conservative to assume equal interest-rate changes on the asset and liability sides for non-life insurers. 
The SCR for the interest-rate increase risk - for life insurers and accident insurers (with premium return business) - is determined using the following formula:

$$
\begin{aligned}
S C R_{\text {interest-rate increase }}= & \max \left(S C R_{\triangle M V, \text { interest-rate increase }}\right. \\
& \left.+S P_{\text {interest-rate increase }} \cdot S C R_{\text {Lapse }}^{\text {Life }} ; 0\right) \\
& -E_{\text {interest requirement }}
\end{aligned}
$$

with class factor $S P_{\text {interest-rate increase }}=1$ for life and accident insurance with premium return $(\mathrm{APR})$, otherwise $S P_{\text {interest-rate increase }}=0$, and $E_{\text {interest }}$ requirement $=$ income from basic requirement.

For the purpose of calculating the $S C R_{\text {lapse }}$, the total portfolio of insurances is divided in three sub-portfolios depending on the surrender value: the first subportfolio comprises all insurances for which a surrender value is guaranteed. The second sub-portfolio consists of those contracts for which only the current value is paid in case of surrender. Contracts without surrender value are the third subportfolio; if, for reasons linked to data processing, the latter cannot be precisely defined, it is included in the second sub-portfolio.

With respect to the sub-portfolio with guaranteed surrender values the hidden reserves on the liabilities side must be added to the capital requirement for the insurance contracts expected to be cancelled after the interest shock, because these reserves will no longer be available for the company. They can be calculated as follows:

$$
\begin{aligned}
& S C R_{\text {Lapse }}^{\text {Life/APR }}(\text { guaranteed portfolios }) \\
& \quad=s q \cdot A n t_{\text {garBest }}\left(B V_{L I}-M V_{L I}\left(1-D_{L I}^{\text {mod }} \cdot \Delta\right)\right)^{16}
\end{aligned}
$$

where $s q$ is the lapse ratio after interest shock for portfolios with guaranteed surrender values (for explanation see formula (5.13)), and $A n t_{\text {gar Best }}$ the share of portfolios with guaranteed surrender values in total of interest-bearing liabilities.

For the sub-portfolio where in case of surrender the current value is to be paid, the difference between the current value and the market value of guaranteed benefits must be taken into account. ${ }^{17}$ Since this is difficult at the moment, it is done on a compound basis using the following formula:

$$
\begin{aligned}
& S C R_{\text {Lapse }}^{\text {Life } / A P R} \text { (portfolios with current values) } \\
& \quad=g s \cdot A n t_{\text {current values }} \cdot M V_{L I} \cdot A W S_{\text {current values }}
\end{aligned}
$$

where $g s$ is the basic lapse ratio of the company, Ant current values the share of portfolios with surrender value $=$ current value in interest-bearing liabilities, and $A W S_{\text {current values }}$ is the standardized divergence between current value and market value of guaranteed benefits as per cent of market value. At present, a figure of 10 per cent is used; after the

${ }^{16}$ In a simplified way, it is assumed that the modified duration of the sub-portfolios is equal to that of the total portfolio.

${ }^{17}$ In the methods for the definition of the current value which are discussed at the moment, the latter differs from the market value of guaranteed benefits, because these are based on the return yielded on the assets side. 
method for determining the current value has been finally established, this figure must be reviewed.

Consequently, the following applies:

$$
\begin{aligned}
S C R_{\text {Lapse }}^{\text {Life } / A P R}= & S C R_{\text {Lapse }}^{\text {Life/APR }}(\text { guaranteed portfolios) } \\
& +S C R_{\text {Lapse }}^{\text {Life/APR }} \text { (portfolios with current values) }
\end{aligned}
$$

The following method is proposed for the calculation of the lapse ratio after an interest shock for portfolios with guaranteed surrender values:

$$
s q=\min (s f \cdot b q+\text { surcharge }+g s ; 100 \%)
$$

The cancellation rate $s f$ is computed as follows:

$$
s f=\max \left(r_{\text {market }}+\Delta-p ; 0\right) \cdot 100 \cdot \frac{r_{\text {market }}+\Delta}{p}
$$

where $b q$ is the basic rate (calibration for entire sector), $g s$ the basic cancellation rate (assessed separately for each individual company), surcharge the security surcharge to the basic lapse ratio (at present 20 per cent points), $r_{\text {market }}$ the interest rate for the 10year Euro swap rate ${ }^{18}$ as of 31 December of the accounting year (accounting year $=$ preceding a.y.), $p$ the current net interest rate on obligations (including current profit shares) and $\Delta$ the interest shock.

It is assumed that the ALM cancellation rate depends on the difference between the interest rate for 10-year Euro swaps after occurrence of the interest shock and the current net interest rate for liabilities. The greater the difference, the higher the tendency of policyholders to terminate their policies. An assumed basic cancellation rate acts as a basic reference value for the cancellation factor.

Basic requirement/interest requirement The previous calculation only took into account the impact of changes in the interest rate. However, the changes in portfolio based on current income from fixed-income titles and necessary changes in technical provisions in the reporting year have not been included. In order to avoid having to integrate a market value-based projection for the closed portfolio into the model, the difference between positive and negative coupons (discounting factor) is used as an approximation for non-life insurers and, for life insurers and accident insurers (including the APR business), the difference between current returns on the fixedincome portfolio at market value ${ }^{19}$ and the solvency requirement resulting from the average technical rate in calculating the SCR for the interest-rate risk. This difference yields the simplified net cash flow from interest activity at the end of the year. This difference may certainly serve to reduce the risk. The current income from the fixed-

\footnotetext{
18 This is considered a risk-free interest rate in the model.

${ }^{19}$ Instead of actual total coupons minus reversal of premiums/discounts, the product of fixed-income market value and current income is used as an approximation.
} 
income portfolio is estimated for the average residual term of the fixed-income portfolio using the Euro swap rate.

This requirement, whether positive or negative, is defined by the following formula

$$
\begin{aligned}
E_{\text {interest requirement }}^{L \text { ife } / A P R}= & M V_{F I} \cdot r_{\text {residual term } F I}-B V_{L I} \cdot\left(M R Z+r_{\text {direct credit }}\right) \\
& -1 \frac{1}{2} M R Z \cdot \text { established current profit shares }
\end{aligned}
$$

where $M R Z$ is the mean technical interest rate of the insurance portfolio (mean value computed by the amount of mathematical provisions), $r_{\text {residual term } F L}$ the market interest rate of Euro Swaps with residual term of fixed-income titles, and $r_{\text {direct credit }}$ the direct credit as percentage of $B V_{L I}$ or

$$
E_{\text {interest requirement }}^{\text {Claim }}=M V_{F I} \cdot r_{\text {residual term } F I}-M V_{L I} \cdot r_{\text {residual term } L I}
$$

where $r_{\text {residual term } L I}$ is the market interest rate of Euro Swaps with residual term of interest-bearing liabilities for non-life insurers.

\section{Currency risk}

The foreign currency risk takes into account potential losses from exchange rate fluctuations. Such fluctuations pose a risk if the claims by insured persons are denominated in a currency other than that of the investments covering those claims (non-hedged). If there is no currency hedging, a risk arises if the asset currency declined in value relative to the obligation currency. The risk bearer for the foreign currency risk is the unhedged market exposure in fixed-interest titles and real estate. The equities investments of insurance companies are increasingly diversified on an international scale, so that currency-related volatility in the equities portfolio is declining due to this effect. The model is based on the principle that the overall risk of a foreign-currency equities portfolio plus fluctuation in exchange rates may not exceed the equities risk in the local currency. Based on this principle, the foreign currency risk of equities is set at zero.

Normal distribution is assumed for the currency risk. The expected earnings are set at zero, like the correlations, since the latter are not stable over time.

Based on these definitions, the following risk factors currently result relative to other currencies from the 0.5 per cent quantile of the corresponding normal distribution (see Table 3):

Table 3

\begin{tabular}{lccc}
\hline & $\begin{array}{c}\text { Volatility } \\
(\%)\end{array}$ & $\begin{array}{c}\text { Risk factor }(R F) \\
(\%)\end{array}$ & Risk bearer $(R B)$ \\
\hline US Dollar (USD) & 10.2 & 26.3 & $\begin{array}{l}\text { Unhedged market exposure of fixed-income } \\
\text { titles and real estate in the relevant currency }\end{array}$ \\
Pound (GBP) & 7.5 & 19.3 & \\
Yen & 11.0 & 28.3 & \\
$\begin{array}{l}\text { Other European } \\
\text { currencies }\end{array}$ & 10.0 & 25.8 & \\
\hline
\end{tabular}


Not listed currencies are to be taken into account at least with the highest risk factor stated. Particularly volatile currencies must be examined separately.

\section{Aggregation of the market risk}

In order to aggregate the individual equities, real estate, interest rate and currency risks, the co-variance formula is applied under the standard method. For the interestrate risk, the basic requirement is represented in the aggregation as income (or loss), to a certain extent. The relevant earnings expectations have already been formulated for the equities and real estate risk.

The correlations between interest rate, equities and real estate development can be studied empirically. However, those correlations have fluctuated very sharply in the past and show high instability over time. For the currency risk and other market risks, the relevant correlations have been set at zero.

Since a market interest-rate increase and a market interest-rate decrease never occur simultaneously, the maximization method is applied in the aggregation of these risks. It must be kept in mind that the sign of the correlation between equities and interestrate risk changes according to whether the interest-rate increase or decrease risk is considered.

Therefore, the SCR and income for the market risk are calculated as follows:

$$
\begin{aligned}
& S C R_{\text {market }}^{\text {interest-rate increase }}
\end{aligned}
$$

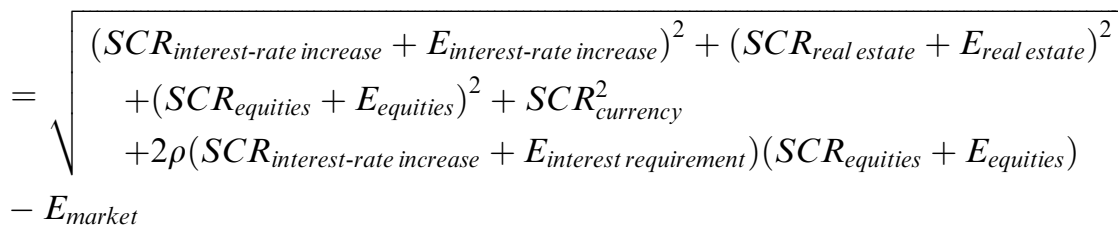

$$
\begin{aligned}
& S C R_{\text {market }}^{\text {interest-rate }} \\
& \left(S C R_{\text {interest-rate decrease }}+E_{\text {interest requirement }}\right)^{2} \\
& =\sqrt{\begin{array}{l}
+\left(S C R_{\text {real estate }}+E_{\text {real estate }}\right)^{2}+\left(S C R_{\text {equities }}+E_{\text {equities }}\right)^{2} \\
+S C R_{\text {currency }}^{2}-2 \rho\left(S C R_{\text {interest-rate decrease }}+E_{\text {interest requirement }}\right) \\
\left(S C R_{\text {equities }}+E_{\text {equities }}\right)
\end{array}} \\
& -E_{\text {market }}
\end{aligned}
$$

where $\rho$ is the correlation between equities and bonds (at present - as per 31 December 2005, 10 per cent).

$$
\begin{gathered}
E_{\text {market }}=E_{\text {real estates }}+E_{\text {shares }}+E_{\text {interest-rate requirement }} \\
S C R_{\text {market }}=\max \left(S C R_{\text {market }}^{\text {interest-rate increase }} ; S C R_{\text {market }}^{\text {intereste decrease }}\right)
\end{gathered}
$$




\section{Concentration risk}

With regard to the concentration risk, which results from little spread of investments, the approach is based on the limits according to European Directives. In the future, it will not be the book values, as is currently the case, but the market values of investments which are to be used as a basis.

\section{Aggregation of the SCRs into the overall G1 risk}

A covariance formula is used for the aggregation of the individual risks under the standard method. The corresponding earnings expectation for the market risk has already been formulated and a subtotal derived. For the credit and default, and concentration risk, the expected earnings value is zero. ${ }^{20}$ In addition, it was assumed that concentration, credit and default and market risks are not correlated.

In light of the values defined in the above sections for risks from investments, the overall G1 risk is calculated as follows:

$$
S C R_{G 1}=\sqrt{\begin{array}{l}
\left(S C R_{\text {market }}+E_{\text {market }}\right)^{2} \\
+S C R_{\text {credit }}^{2}+S C R_{\text {concentration }}^{2}
\end{array}}-E_{\text {market }}
$$

with

$$
E_{\text {market }}=E_{\text {real estate }}+E_{\text {equities }}+E_{\text {interest requirement }}
$$

\section{Calculation of the underwriting risk}

Due to the particularities of specific classes, this risk category is modelled differently for life and casualty/property/accident insurers.

\section{Life ( L risk)}

Underwriting risks for life insurers can be subdivided into:

- costs risk;

- default risk of receivables due from agents and policyholders;

- biometric risk.

Since a quantile-based approach seems hardly possible, these sub-risks are reflected via risk scenarios. This approach is consistent with the IAA proposals suggesting such a procedure.

In the case of the costs risk, which arises from possible changes in cost structures, it is assumed that in the following year a discontinuation of new business occurs with the company nevertheless having to incur expenditure to the amount of the fixed acquisition costs and administrative expenses. To the same amount, capital has to be

\footnotetext{
${ }^{20}$ This means, for example that $E W_{G 1}=E W_{\text {market }}$.
} 
provided for this risk. However, deductions are allowed for the income from expenses derived from business in force, amortization loadings and the balance from other income and other expenditure.

Another risk is constituted by the default of receivables due from agents and policyholders. First, the reduction of Zillmer claims due to the premature termination of contracts less reversed commission entries due to premature termination plus depreciation and value adjustments regarding receivables due from insurance agents is determined. In this respect, the value is considered in relation to Zillmer claims and receivables due from insurance agents.

The biometric risk is composed of the fluctuation, cumulation and trend risks which are modelled separately:

- Fluctuation risk: In this case, standard deviations of the distributions - separately for insurances against death, on survival, occupational disability insurances and remaining insurances - are approximated, with the size of the portfolio, the actual expenditure and the capital at risk being included as parameters. In accordance with the preset quantile, the risk capital is determined as a multiple of the distribution.

- Cumulation risk insurances against death/occupational disability insurances: In the case of this risk, it is assumed that risk expenditure will double over the preceding year. The actual expenditure is deducted from the risk expenditure. The risk capital is once again maximized over the three preceding years.

- Trend risk: Here, annuities only are considered. As risk capital a proportion of the mathematicial provisions for annuities is assumed.

\section{Non-life (NL1 and NL2 risks)}

The insurance technique of a casualty/property/accident insurer is reflected by considering the following sub-risks:

- premium and provisioning risk;

- failure-of-reinsurance risk.

The premium and provision risk (NL1 risk) reflects the risk arising from application of insufficient premium rates and insufficient provisions. At first, the business of a casualty/property/accident insurer is divided into 11 lines of business (LoB), based on the First Non-Life Coordinating Directive.

The risk capital requirement is calculated using the company's individual combined ratios for each line of business, taking into account the correlations among the lines of business calculated on market basis. In addition, it is considered whether a company applies insufficient or sufficient premium rates to a class. Similar to the life model, risk bearer and risk factor per LoB are multiplied. For reasons of simplification only proportional reinsurance is taken into account. A conservative estimate is made of the correlations applied, so that the model takes diversification effects into account (as they are typical of the activity in an insurance company), but still provides incentives to work on internal models. Another important advantage of the model - contrary to 
other proposals put forward in the international debate - consists in the fact that a standard model is based on internal company data and that nevertheless the approach remains sufficiently simple.

Unlike in the first version of the model, the risks related to premium rates and provisioning are integrated. This procedure is aimed at preventing the model from providing false incentives, for instance, if in the provisioning risk, where the provisions would serve as a risk bearer, the own funds requirements rose in line with the increase in provisions. In addition, the following reasons may be given for such an integrated approach: It seems right to use the combined ratio because this way the model can fall back on internal company data which can be easily verified by the supervisory authority. If the premium risk and the provisioning risk are separated, this results, especially in small companies, in greater instability of the data than if the calculation is effected based on the combined ratio. Moreover, - as is shown by some test calculations - the combined ratio is the more stable measure in the case of transition to the fair value approach because artificial volatilities may arise in particular on the provisions side.

As usual in international debates natural disaster risks have been integrated into the non-life model. Natural disaster risks are treated in the model as separate LoB with a zero correlation towards other lines of business. The basis is a market loss distribution. The premium portion related to natural disaster risks is derived from market data as a loss portion of all identified severe losses and preset as a uniform percentage in the model. Reinsurance cover - proportional or non-proportional - is taken into account. For the purpose of simplification, only storm risks are included in this first step. A later modelling of further natural hazards is possible. For reasons of simplification, the model does not take into account regional differences between the exposures of individual insurance companies in Germany or company PMLs (Probable Maximum Loss). Such a procedure is left to internal models.

In addition, the failure-of-reinsurance risk ( $N L 2$ risk) is modelled. In the new model, the risk factors are determined on the basis of the system applied by major rating agencies. Reinsurers rated inferior to $\mathrm{BBB}$, but submitted to the supervision by European authorities, are weighted by the probability of failure on which the supervisory concept for reinsurers is based.

\section{Reflection of the operational risk}

The operational risk is generally defined as the risk of losses occurring as a result of inadequacy or failure of internal procedures, persons or systems or due to external events. The own funds requirements to this effect are calculated in the model as the maximum of a percentage of gross premiums earned and of a proportion of technical provisions.

\section{Conclusion}

The submitted proposal is compatible with the requirements imposed by the EU Commission in its working documents within the "Solvency II" project and which 
have become apparent, for instance, in the first CEIOPS Interim Report. ${ }^{21}$ At the same time, it meets the requirements put forward by the IAA. Therefore, the model approach proposed is to be understood as a contribution to the discussion within the scope of the "Solvency II" project and intends to demonstrate how the various questions raised by the EU Commission within the scope of this project in the context of the standard approach and to be clarified can be solved. As a positive aspect, it can be pointed out that many proposals for modelling that have been submitted as to their main features have been included in the CEIOPS Interim Report. It is planned to continue to bring the standard model actively into the international debate so as to influence European reflections in this respect and to have the German business model reflected in a risk-adjusted manner in the standard approach. Moreover, the approach, which has a modular structure, can be easily adjusted to the circumstances existing in other countries. At the same time, however, it is foreseeable that no purely national proposal can be enforced at European level and that only a common solution between EU member countries can be achieved in this respect.

\section{References}

CEIOPS (2005a) 'Draft answers to the European Commission on the "second wave" of calls for advice in the framework of the Solvency II project', www.ceiops.org, $\rightarrow$ Consultations $\rightarrow$ Consultation Papers.

CEIOPS (2005b) 'Amended framework for consultation on Solvency II', http://www.ceiops.org/texte/ solvII_framework_ec.pdf.

GDV Model (2002) 'Neues Aufsichtsmodell für europäische Versicherungsunternehmen', http:// www.gdv.de/fachservice/20716.htm.

IAA (2004) A Global Framework for Insurer Solvency Assessment, Report by the Insurer Solvency Assessment Working Party, IAA, Ottawa, Canada.

Standard Approach (2005) 'Discussion paper for a Solvency II compatible standard approach (Pillar I), Model description (version 1.0 of 1st December 2005)', http://www.gdv.de/Themen/Rechnungslegung und_Projekt_Solvency_II/Rechnungslegung_und_Solvency_II_Hintergrundinformationen/ inhaltsseite756.html.

\section{About the Authors}

Dr. Thomas Schubert is Head of the Business Administration Institute, GDV. Gundula Grießmann formerly worked in the Business Administration Institute, GDV.

\footnotetext{
${ }^{21}$ Cf. CEIOPS (2005a, b).
} 